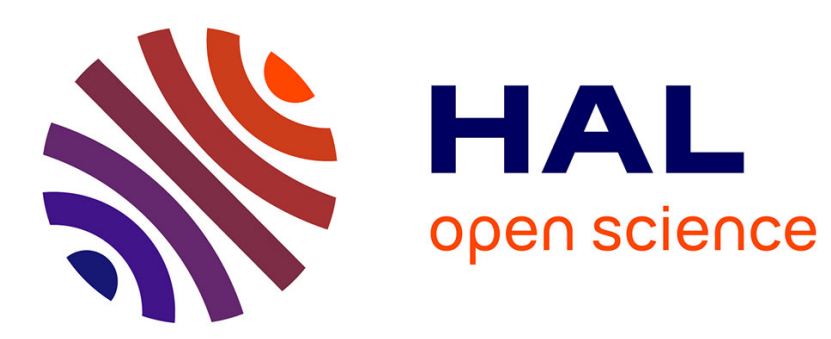

\title{
Problem-Based Learning Approach to Teach Printed Circuit Boards Test
}

\author{
Béatrice Pradarelli, Pascal Nouet, Laurent Latorre
}

\section{To cite this version:}

Béatrice Pradarelli, Pascal Nouet, Laurent Latorre. Problem-Based Learning Approach to Teach Printed Circuit Boards Test. ICL: Interactive Collaborative Learning, Sep 2016, Belfast, United Kingdom. pp.45-57, 10.1007/978-3-319-50337-0_4 . lirmm-01385626

\section{HAL Id: lirmm-01385626 https://hal-lirmm.ccsd.cnrs.fr/lirmm-01385626}

Submitted on 21 Oct 2016

HAL is a multi-disciplinary open access archive for the deposit and dissemination of scientific research documents, whether they are published or not. The documents may come from teaching and research institutions in France or abroad, or from public or private research centers.
L'archive ouverte pluridisciplinaire HAL, est destinée au dépôt et à la diffusion de documents scientifiques de niveau recherche, publiés ou non, émanant des établissements d'enseignement et de recherche français ou étrangers, des laboratoires publics ou privés. 


\title{
Problem-Based Learning Approach to Teach Printed Circuit Boards Test
}

\author{
Beatrice Pradarelli, Pascal Nouet, Laurent Latorre \\ University of Montpellier \\ Polytech Montpellier/LIRMM/Montpellier CNFM center \\ Montpellier, FRANCE \\ beatrice.pradarelli@lirmm.fr
}

\begin{abstract}
This article presents a return of experience of a collaborative educational approach put in place to build a new course about the test of Printed Circuits Boards (PCB). This course was dedicated to $5^{\text {th }}$ year engineer apprentice students from Montpellier Polytech School. The teaching method followed the "problem-based learning" (PBL) approach, which is a student-centered pedagogy: the students learn ingroup about a topic (knowledge and know-how) through the experience of solving an open-ended problem proposed by the teacher. This approach targets two types of objectives: technical with the learning of PCB test methods and educational with the learning of thinking strategies, decision-making, negotiation and collaborative work. A course evaluation form has been created, based on the F2A Louvain University one, to help the students providing classifiable feedback about this "problem based learning" approach.
\end{abstract}

Keywords: problem based learning; collaborative; education; evaluation; skills; competencies; PCB test; risk analysis;

\section{Introduction}

In 2014-2015, a new course relative to printed circuit boards (PCB) testing has been added to the syllabus of the $5^{\text {th }}$ year Embedded Systems curricula of Polytech Montpellier engineering school. $5^{\text {th }}$ year Embedded Systems students are engineer apprentices students who, since the $3^{\text {rd }}$ year at Polytech school, spend half of a month attending courses and studying and, the remaining half working for a company. In order to position them in a teaching context close to their real world working, the teacher freshly trained to problem-based learning approach from Louvain University teachers [1] decided to apply this student-centered pedagogy to the PCB testing course. Students would learn in-group about a topic (knowledge and know-how) through the experience of solving an open-ended problem proposed by the teacher. The choice of the problem-based active teaching approach was appropriated to motivate the students elaborating a learning strategy where they were protagonists of their learning and the teacher's role was only to guide them to be skilled before the visit of a PCB manufacturing and test plant organized in order to compensate the lack of lab material for practice.

This paper presents a return of experience of the "problem based learning" (PBL) approach developed to teach PCB testing and is composed of several sections. Section II is dedicated to the description of the context of PCB manufacturing and test. Section III briefly introduces the Electrical Engineering department of Polytech Montpellier engineering school. Section IV presents the problem-based learning approach concepts, its process phases, its organization and the impacts on the teacher's role. Then section IV describes how the PBL concepts have been applied to the PCB testing course and the technical and pedagogical objectives. Section $\mathrm{V}$ presents the outcome of this new student-centered teaching method while the section VI states about the required preparation to implement this collaborative approach and the improvements that could be applied. Section VII is the conclusion of this return experience of collaborative learning and the perspectives.

\section{Printed Circuits Boards manufacturing and test}

A printed circuit board (PCB) is a thin board made by combining different sheets of non-conductive material like fiberglass, composite epoxy, plastic or other laminate material that easily holds copper circuitry. The conductive pathways are etched or "printed" onto board, connecting different surfacemounted and socketed components on the PCB, such as transistors, resistors, and integrated circuits (IC).

PCBs manufacturing first requires designing the board with CAD tools and then fabricating it through several chemical operations.

PCBs are used in both desktop and laptop computers. They serve as the foundation for many internal computer components. Even if PCBs are often associated with computers, they are used in many other consumers' electronic devices like TVs, radios, digital cameras, cellular phones, and tablets and all of them include one or more printed circuit boards. Figure 1 shows the photograph of a PCB with soldered components. 


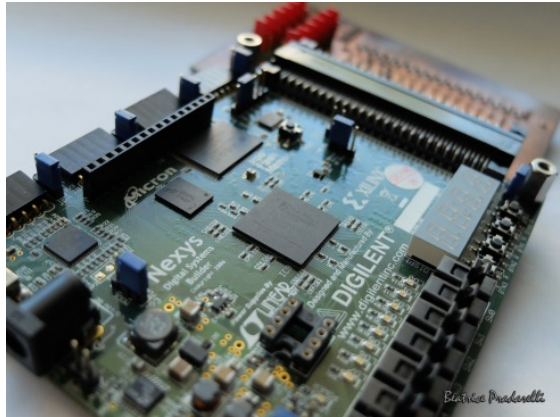

Fig. 1. Photograph of a mounted PCB.

PCB testing targets several objectives and happens at different stages of the board manufacturing. Only the main tests are briefly described here. The first test consists in verifying that the naked printed circuits (before soldering any component) are free of any damaged conductive pathways and missing printed note-pad. Verifying the soldering process is part of the second test as well as checking the soldered components presence, value, polarization and alignment. This step of verifications is performed either with an AOI (Automated Optical Inspection) machine or an AXI (Automated X-ray Inspection) one, which both scan every PCB going of the soldering process. Then, an electrical test is executed using a bed of nails or a flyer probe tester to check voltages between nodes. Each of these tests requires dedicated method and test equipment.

\section{$3 \quad$ Embedded System Engineer Students @ POLYTECH MONTPELLIER}

Polytech is an engineering school inside the University of Montpellier, which offers to students starting their $3^{\text {rd }}$ year of study in the Electrical Engineering department, the choice between 2 curricula: "MEA" (Microelectronics Electronics \& Automation) and "ES" (Embedded Systems). The students who will select the "ES" curricula will become apprentice students during 3 years and will spend half of a month attending courses and studying and, the remaining half working for a company. The students who will choice "MEA" curricula will be full time studying at the school.

Both future engineers will be able to work in the same fields like the consumers' electronics, automotive, air space and military ones but at different levels: "MEA" engineers will deal with integrated circuits and "ES" engineers will manage systems (from PCB to satellite).

\section{$4 \quad$ Problem Based Learning Approach}

\subsection{Choice of the teaching approach}

In 2014-2015, a new course relative to the test of printed circuit boards has been added to the syllabus of the $5^{\text {th }}$ year Embedded Systems curricula. To get students fully skilled in this discipline, it was necessary to provide them knowledge from lecture and know-how from labs. Unfortunately, no test equipment (bed of nails, AOI or AXI) that would have allowed students acquiring practise in PCB testing technics was available at the school. To compensate this lack of lab material, the teacher organised the visit of the Company OMICRON [2] located nearby Montpellier, which was a PCBs manufacturing and test plant. To benefit from the learning of this visit, the teacher wanted the students to know the basics about PCB testing in order to be active and ask questions during the company tour.

Because "ES" students are apprentices working for a company half of their time, the teacher chose Problem-Based Learning (PBL) approach to set up the course into a teaching context close to their real world working. Students would learn ingroup about PCB testing through the experience of solving an open-ended problem proposed by the teacher. The challenge was to motivate the students collaborating to define in-group a learning strategy that would have promoted individual and teamwork and achieve the learning objectives. The teacher's role was only to guide them to get skilled.

\subsection{Educational approach organization}

Dedicated course syllabus and training material have been elaborated to match the PBL approach (based on the FA2L Louvain teachers 'manual), which basis consists of two sessions of collaborative work and time in between (2-3 weeks) during which students study individually.

The $12 \mathrm{hrs}$ of the course were distributed as follow: $4 \mathrm{hrs}$ for the PBL approach itself, $4 \mathrm{hrs}$ for the visit of a PCB manufacturing and test plant, 3 additional hours to allow the students finishing solving the open-ended problem and working on their final report, and $1 \mathrm{hr}$ during which the students evaluated their learning outcome in this particular teaching approach. The course ended with a cake party. The exact course schedule is described in table I.

The beginning of the first session ( $2 \mathrm{hrs}$ ) was dedicated to the presentation of the PLB approach and the learning objectives to the students: "Go" and "Return" sessions agenda, the students' role inside the group, the problem they had to solve ingroup and the learning strategy they had to define. It was crucial that they understood the teacher's expectations about their collaborative and individual learning in order to achieve the course goals. The classroom organization was modified to look like a meeting room facilitating the group discussions. Paper and white boards were also provided. 
Table 1. PCB TESTING COURSE ORGANIZATION

\begin{tabular}{|l|l|l|}
\hline Date & Title of the session & Hrs \\
\hline $15 / 3 / 4$ & PBL Go session: collaborative work & $2 \mathrm{~h}$ \\
\hline & Individual work at home & \\
\hline $15 / 4 / 1$ & PBL Return session: collaborative work & $2 \mathrm{~h}$ \\
\hline $15 / 4 / 8$ & OMICRON's visit & $4 \mathrm{~h}$ \\
\hline $15 / 5 / 6$ & Collaborative work on risk analysis \& report & $3 \mathrm{~h}$ \\
\hline $15 / 5 / 25$ & Student's learning self-evaluation \& Cake party & $1 \mathrm{~h}$ \\
\hline
\end{tabular}

\subsection{Teacher's role}

In the PBL approach the teacher's role is to guide the students to solve in-group the open-ended problem [1, 3, 4]: he had to diagnose any obstacle (conflict inside the group, misunderstanding of the problem) that would alter each group's progress according to the procedure. He also had to question indirectly the students about their previous know-how of the problem context to orient the discussion and he had to facilitate the exchange of ideas, the negotiations and communication inside the groups.

\subsection{Course progress}

\section{Problem Based Learning approach presentation to stu- dents}

First, the teacher explained to the 12 students (only men) the motivation of the teaching approach choice. Then, she presented the teaching method it-self: an open-ended problem will be proposed to the students and they will have to solve it in-group, without having any preliminary course. Students will have to identify what they already knew about the topic, what they needed to learn, and how and where to access the information that would lead to the resolution of the problem. It was clearly mentioned to the students that the allocated time to work in-group on the problem in the classroom was limited to 2 sessions (Go and Return ones) of $2 \mathrm{hrs}$. So, each group had to identify the 3 or 4 members that will animate both sessions: the leader (who lead the group's discussion during the session), the moderator (who checked the schedule and took care of any logistics aspect), the scribe (who was the instant memory of the group's ideas, concepts and questions) and the secretary (who took notes during the session and sent the minutes back to all group members). The number and the title of these roles can slightly change from one PBL usage to another.

Between the 2 sessions, each student was expected to perform individual work. The teacher concluded presenting the technical and educational objectives. Getting skilled in PCB test concepts and risks analysis methodology and practice were the technical goals. Cooperate actively within the group to the definition of the learning strategy, individually acquire technical knowledge and share it to the group to build collaboratively the competencies allowing the team to solve the initial problem were the educational targets.

\section{Collaborative work during the "Go session"}

During the "Go" session, two groups of 6 students were created based on students' friendship. One group was composed of 5 good classmate students. The $6^{\text {th }}$ member had his friend in the second group, which gathered the remaining students, some of them also being good classmates.

Each group received from the teacher the same note-pad describing the problem to solve, the step by step procedure and the timing to follow to collaboratively understand the problem, identify their prior-knowledge and ignorance to end it having established a learning strategy plan that each student would performed before the "Return session".

The first step of the procedure was to assign a role to at least 4 group members: the leader, the moderator, the scribe and the secretary. The group composed of the good classmates who approved the learning approach, shown a high motivation and quickly performed this task. The second group, composed of only 3 motivated students over 6 , met the first signs of internal conflicts at this step as none of the 3 remaining students wanted to take a role. The teacher neither forced the missing assignment nor questioned the reluctant students about their motivation but rather reminded the timing and the objectives of the "Go session" to the group. Facing the fact that their lack of collaboration would penalize the whole group, the unenthusiastic students started cooperating.

In the second step, the students of each group had to read the open-ended problem statement, to highlight the important words and to list the raised questions, the misunderstood or unclear items. The leader had to collect all inputs from the team members, which were written on a white board by the scribe. The moderator had to take care that this task was performed within 10 minutes.

In the third step, the group had to provide a summarized reformulation of the problem to be sure that the mission was understood and a list of deliverables: to deliver a risk analysis template relative to PCB tests. The secretary had to consign this information. The allocated time was 15 minutes.

The next step was to make a status of the group members' current knowledge about the topics of PCB manufacturing and test, and risk analysis methodology. It was the first time when the cooperation of each group member presenting his knowledge contributed to build the group knowledge. So, this stage was important because the learning strategy of a group depended of its individual's erudition on the topic. The teacher had to carefully watch the communication inside each group to check that each student gave his statement and opinion. If not, he had to question the leader to make him realizing his mistake. 30 minutes were allocated to this task.

The $5^{\text {th }}$ step consisted in 15 minutes to list the learning objectives to solve the problem with the assessment conditions for each goal.

The $6^{\text {th }}$ and last step of the "Go session" was the creation of a Gantt chart describing each task with its duration, allocated resource (documentation) and owner(s), and the list of deliverables to produce. It was important that the students identify the 
tasks directly linked to the learning objectives, to keep them focused.

The group with the 6 motivated students went through all the 5 steps after the roles assignment without any major problem. The behavior of the 3 unwilling students of the second group, the authority issue that faced the leader and the lack of interaction from the teacher often conduced the group to unorganized discussion, unstructured animation, no teamwork collaboration and a communication restricted to some members. Laboriously, the group followed each procedure step and established a learning strategy plan at the end of the "Go session".

\section{Individual work}

During the 3 weeks separating the "Go" and "Return" sessions, the students had to read the documents provided in the note-pad according to the learning strategy both groups had defined. Each student read all the documentation in order to acquire alone the entire requested knowledge to solve the problem, focused on a particular topic and produced a summary he will share with the group during the "Return session".

Even if it was not requested, each group sent to the teacher a report of the "Go session" which detailed its Gantt chart.

\section{Collaborative work during the "Return session"}

During the "Return session" (2hrs) 3 weeks later, both groups discussed their findings and started elaborating together a solution based on what they learned individually.

Once again, they followed a step-by-step procedure. First, each group organized, in 10 minutes, the assignment of the leader, moderator, scribe and secretary roles. They decided to keep their previous ones even if the teacher suggested them changing.

The second and main step (50 minutes) was the synthesis of the learning. It required the cooperation of each group member who had to share the outcome of his individual work. Any student who would not have performed his assigned task would impact the technical learning objectives of the group. The individual work was crucial for the group collaborative success. Once again, one group achieved almost straight forwards this synthesis task, whereas the other one faced team conflicts. The passive behaviour of the 3 students influenced a lot team spirit and its outcome as the group ran out of the time allocated to this procedure step.

One again, both groups produced a report of the "Return session".

\section{Visit of OMICRON Company and outcome}

The director spent 3 hours presenting the different PCB test steps and equipment to the students. Thanks to the students' involvement in the active learning approach, most of them were able to link the test concepts and technics they learnt to the real usage of the equipment during the demonstrations. All students were happy of the visit and admitted that the experi- ence would not have been so fruitful with a classic lecture teaching method in which they would not have been the protagonists of their learning.

\section{Students 'skills evaluation}

The students had to deliver one risk analysis report per group about the test technics applied to verify PCB based on the knowledge they acquired reading documentation selected by the teacher and the outcomes of the visit.

\section{Students' learning self-evaluation}

Individually, the students had to evaluate their learning in the context of the PBL approach. They had to complete a dedicated form developed based on an evaluation form from FA2L Louvain teachers [1].

Three main sections composed the document. They were organized as follow:

Student's evaluation of the group performances. Using a spider diagram (see figure 2), they had to rank the following criteria:

- Group learning outcome: the group produced something satisfactory, this production was really the result of a collective effort, the meetings were effective, the exchanges allowed bringing to the foreground different points of view to handle the problem.

- Group members' investment and communication: each of the participants contributed significantly to the efficiency of the group, the group gave the opportunity to each of his members to express its point of view even to the passive participants, all the members of the group proposed their individual work done between both sessions

- Relationship with the teacher: in a general way, the group took advantage of the teacher's presence and guidelines to progress.

- Relationship with the learning context: the group became quickly motivated to work the theme; the group found that the problem was well adapted to the members that it was enough complex and rich enough for a meaningful learning.

- Group organization: the group succeeded in coordinating its activities, the group remained centred on the task to be carried out, the group made a good use of the white board, the secretary kept tracks of the exchanges, the leader played its role and the timing was respected

- Atmosphere in the group and in the working context: the agreement between the members of the group was good, the participants encouraged each other's, the group managed to surmount its differences of view, and nobody managed to impose his point of view.

The ranking scale was from 1 to 4 with the following meaning: $1=$ not satisfying; $2=$ not really satisfying; $3=$ satisfying; 4=very satisfying. 


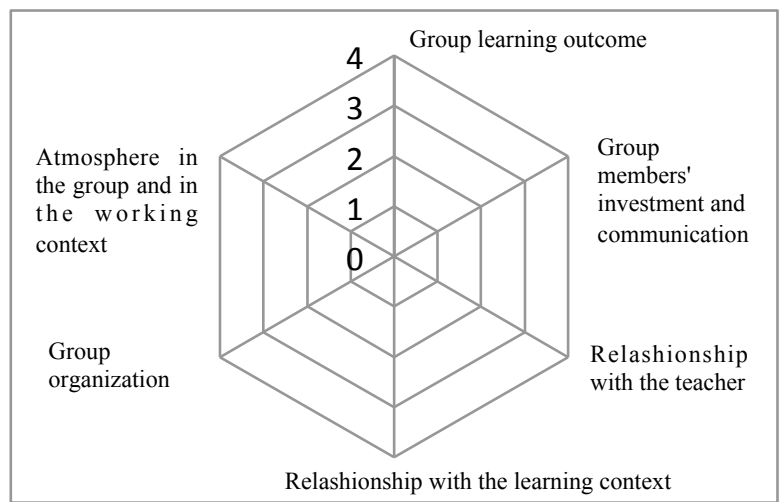

Fig. 2. Spider diagram for the "Problem-Based" approach evaluation by the groups of students

Students 'feedback about the advantages and disadvantages of working in-group to learn skills. Each student had to enumerate the actions that went fine in the context of the teamwork, those ones that did not and what he could personally have done to improve the work in-group.

Student self-evaluation of his learning. For this selfevaluation, the students had to fill a table in which they had to list what they learnt and how skilled they were before and after the course. The ranking scale was from 0 to 5 with the meaning explained in table II. Students had also to specify the number of hours spent studying individually.

Table 2. RANKING SCALE MEANING

\begin{tabular}{|l|l|l|l|l|l|}
\hline \multicolumn{1}{|c|}{$\mathbf{0}$} & \multicolumn{1}{c|}{$\mathbf{1}$} & \multicolumn{1}{c|}{$\mathbf{2}$} & \multicolumn{1}{c|}{$\mathbf{3}$} & \multicolumn{1}{c|}{$\mathbf{4}$} & \multicolumn{1}{c|}{$\mathbf{5}$} \\
\hline $\begin{array}{l}\text { I don't } \\
\text { anything } \\
\text { about } \\
\text { the topic }\end{array}$ & $\begin{array}{l}\text { I } \\
\text { have } \\
\text { heart } \\
\text { about } \\
\text { the } \\
\text { topic }\end{array}$ & $\begin{array}{l}\text { I can say } \\
\text { one or two } \\
\text { things } \\
\text { about the } \\
\text { topic }\end{array}$ & $\begin{array}{l}\text { I can list the } \\
\text { describe main } \\
\text { items of } \\
\text { the topic }\end{array}$ & $\begin{array}{l}\text { I can argue, } \\
\text { relevant } \\
\text { items of the } \\
\text { topic and my } \\
\text { the relation } \\
\text { between } \\
\text { them }\end{array}$ & $\begin{array}{l}\text { statement, } \\
\text { choices and } \\
\text { decisions } \\
\text { about the } \\
\text { topic }\end{array}$ \\
\hline
\end{tabular}

\section{Cake party}

The teacher proposed a cake party to celebrate the end of the course. All students brought food and beverages and shared them as shown on figure 3. Students took this opportunity to give a subjective feedback about the educational approach. The motivated students were very satisfied as they considered they learnt in a collaborative context close their real work. They liked being the protagonists of their learning and it increased their self-esteem to contribute to the group success. The unenthusiastic students explained they did not like the approach because preferred the classic top-down teaching method rather than this student-centered one.

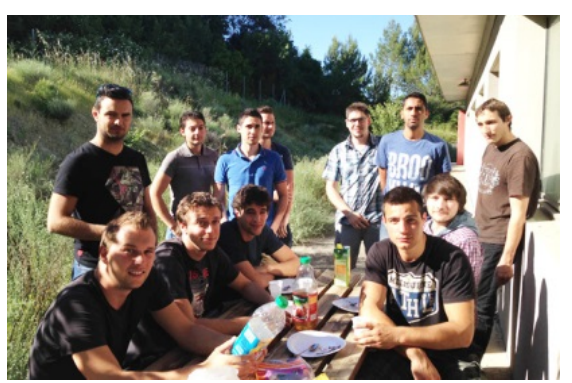

Fig. 3. Photograph of the ES students at the cake party

\section{$5 \quad$ Educational Approach outcomes}

\subsection{Analysis of students 'skill evaluation}

As mentioned earlier, each group produced a summary report of the "Go" and "Return" sessions in addition to the final risks analysis one. Each report was marked. The final mark was the average mark of the 3 reports.

As each member of one group fairly collaborated to solve the initial open-ended problem being all very invested in their own learning as well as in the success of the group, they all obtained the same mark. Concerning the second group, only the 3 motivated students received the highest mark produced by the evaluation of the 3 reports. The 3 others were penalized and lost one point.

This experience shown that evaluating the students' skills using the PBL approach was not an easy task. It was almost not possible to objectively mark the learning a single student acquired during the course. So, when selecting a teaching approach, it is not only important to define the learning objectives but also to identify the "best way" to verify the students have achieved them. The report was an appropriate choice to represent the work produced by each group. But, may be, an additional quiz would have allowed to individually check the students' learning acquisition. As it was the time this course was put in place, there is no reference to compare the students' marks with an estimate the relevance of the teaching approach.

\subsection{Analysis of the students' learning self-evaluation}

This paragraph presents the synthesis and analysis of the students' answers about three sections of the evaluation form.

\section{Student's evaluation of the group performances.}

First, the 12 spider diagrams were studied all together and the average values to the 6 items varied between 3 and 3.38, which were high scores as the maximum value is 4 . So, as a preliminary conclusion, it appeared that all students recognized the interest of the collaborative work.

As 3 students out of 12 clearly shown a lack of motivation to learn in this collaborative context, a second analysis was 
performed on the spider diagrams, this time separating the ones from the motivated students to the unwilling ones. The compilation of numbers obviously pointed out a major difference of appreciation of the collaborative teamwork between the motivated and not motivated students. All the compiled numbers are presented in table III and reported on the spider diagram in figure 4 using a specific color that code is mentioned in the table.

Table 3. RESULTS COMPILATION

\begin{tabular}{|l|c|c|c|}
\hline $\begin{array}{c}\text { Group Per- } \\
\text { formances } \\
\text { /\# Student }\end{array}$ & $\begin{array}{c}\text { 12 students } \\
\text { (Blue dots) }\end{array}$ & $\begin{array}{c}9 \text { moti- } \\
\text { vated stud. } \\
\text { (Black dots) }\end{array}$ & $\begin{array}{c}3 \text { not motivated } \\
\text { stud. } \\
\text { (Red dots) }\end{array}$ \\
\hline a) Outcome & 3.32 & 3.53 & 2.67 \\
\hline b) Investment & 3.17 & 3.34 & 2.67 \\
\hline c) Teacher & 3.38 & 3.17 & 4 \\
\hline d) Problem & 3.13 & 3.17 & 3 \\
\hline e) Organization & 3 & 3.28 & 2.34 \\
\hline f) Atmosphere & 3.5 & 3.8 & 2.67 \\
\hline
\end{tabular}

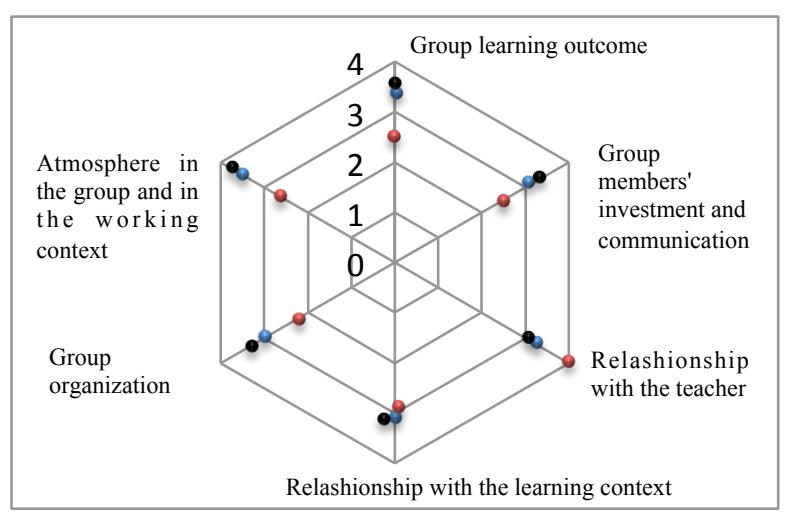

Fig. 4. Graphical representation of the group performances compilation

\section{Students' feedback about the advantages and disad- vantages of working in-group to learn skills.}

The students enumerated the actions that went fine and the ones that did not concerning learning in-group. It appeared that several actions obtained opposite opinions like the assignment of the roles, the atmosphere inside the group, the cooperation of the students, the organization and the distribution of the tasks inside a group that conduced to different workloads between students, the communication inside the group, the animation of the group and the collaboration of each student during the "Return session" to share his outcomes of the whole group.

The students insisted on the fact that the time allocated to perform the procedures during the "Go" and "Return" sessions was too short, in particular to clearly understand the problem and its context. Nevertheless, most of the students were satisfied of the overall process: defining in-group a learning strategy to solve the open-ended problem, studying individually all the documents but focusing on a dedicated topic and sharing their outcome to the whole group to collaboratively allow all members to achieve the learning objectives. All students liked the cake party.

Concerning the actions the students could personally do to improve the work in-group, they mentioned: to be more involve to provide a better collaboration, communicate and helped reaching the learning objectives in less time and in a better team spirit.

\section{Students' learning self-evaluation.}

Even if each student was free to list any relevant learning skill, three main topics appeared from the synthesis of all the lists: knowledge about PCB manufacturing, PCB testing and risk analysis methodology. Each student ranked from 0 to 5 his level of knowledge for each skill before and after the course. The compiled results of all students, of the 9 motivated and 3 unwilling ones are presented in table IV.

It was surprising to discover, from the analysis of table IV, that the 3 not motivated students achieved a better level of knowledge on 2 out of 3 skills compared to the 9 motivated students. Were they over-estimating themselves? The number of hours each students had spent learning was studied and it appeared that the 3 students spent an average time of $6.2 \mathrm{hrs}$ per student studying whereas the 9 motivated ones declared an average of $5.4 \mathrm{hrs}$ per student. This shown that the 3 students who demonstrated a none collaborative behavior wanted to learn to be skilled in these topics but disagreed on the teaching approach.

The analysis of table IV also put on evidence that even if the students improved this initial knowledge on the 3 topics, they were far away to be fully skilled (level 5) at the end of the course.

Table 4. RESULTS SYNTHESIS

\begin{tabular}{|c|c|c|c|c|c|c|}
\hline & \multicolumn{2}{|c|}{12 students } & \multicolumn{2}{c|}{$\begin{array}{c}\text { 9 motivated stu- } \\
\text { dents }\end{array}$} & \multicolumn{2}{|c|}{$\begin{array}{c}\text { not moti- } \\
\text { vated students }\end{array}$} \\
\hline $\begin{array}{c}\text { Knowledge / } \\
\text { \# students }\end{array}$ & $\begin{array}{c}\mathrm{Be} \\
\text { fore }\end{array}$ & $\begin{array}{c}\mathrm{A} \\
\text { fter }\end{array}$ & Before & $\begin{array}{c}\text { Af } \\
\text { ter }\end{array}$ & $\begin{array}{c}\text { Be } \\
\text { fore }\end{array}$ & $\begin{array}{c}\text { Af } \\
\text { ter }\end{array}$ \\
\hline PCB manuf. & 1.92 & 3.1 & 1.89 & 2.89 & 2 & 3.67 \\
\hline PCB test & 1.43 & 3.4 & 1.61 & 3.61 & 0.89 & 2.75 \\
\hline Risk analysis & 0.75 & 2.42 & 0.89 & 2.11 & 0.33 & 3.33 \\
\hline
\end{tabular}

\section{$6 \quad$ Statement \& Improvements}

\subsection{Statement}

Problem-Based Learning approach required a long preparation from the teacher in terms of research on papers, documents, web sites relative to the topics. The teacher has to read all documents to identify the most relevant ones to be proposed to the students in the note-pad.

Despite the fact that the students who studied the documents became skilled on the new topics and able to solve the given problem, the real challenge was to motivate each group 
members to fairly collaborate and to acquire these competencies. The teacher who became a tutor meaning that her role was to guide the students, had to build their confidence to take on the problem, and to encourage them cooperating in this new learning approach, which represented a paradigm shift from traditional teaching and learning philosophy, which was more often lecture-based. This new tutor role was not easy to play.

\subsection{Improvements}

Changes have to be applied to this collaborative educational approach to improve the technical and educational outcomes:

- In order to build a real teamwork spirit and to facilitate the collaboration and communication within the group, groups should not be created based on students' friendship.

- The teacher has to interact more often, in particular when diagnosing any conflict between group members and normalize it, or when the group shows a lack of dynamism du to none fairly collaboration of each member in order to minimize the impacts on the group success.

- The teacher should add regular milestones to check students' knowledge progresses.

- A solution has to be found to allow students practicing and acquiring know-how on these technical topics.

- The teacher has to spend more time explaining the different roles and has to ask the leader and the moderator to respect the timing. May be a game that rules would fit to the PBL ones could be a good way to initiate the students to the new collaborative approach.

- The teacher has to identify the appropriated exam mode to verify each student achieved the technical learning objectives.

\section{Conclusion}

From pedagogical point of view, the "problem-based learning" approach was an interesting experience for the $5^{\text {th }}$ year apprentice engineer students as they discovered an innovative learning method where they were the protagonists of their own learning and which allowed them to study in conditions close to real world work when collaboration is in purpose. For the students, the gains of this approach were the acquisition of technical knowledge in PCB test and risks analysis methods and they got trained in thinking strategies, decision-making, negotiation and collaborative work.

For the teacher, this approach requested a long preparation, as it was necessary to develop dedicated course syllabus as well as course material to fit the PBL approach procedure and the learning objectives. The teacher had to get familiar with his new role of instructor or tutor, which was not a natural thing. He had to facilitate learning by supporting, guiding, and moni- toring the learning process of the students in-group without ordering them.

Based on this first positive experience, the PBL approach will be repeated in 2015-2016 taking into account all the enumerated improvements.

\section{ACKNOWLEDGMENT}

Authors acknowledge the support of the French Agence Nationale de la Recherche (ANR), under grant ANR-11-IDFI0017 (project

IDEFI-FINMINA). 


\section{References}

1. See: http://fa2l.weebly.com

2. OMICRON: www.omicron.fr

3. http://fhs.mcmaster.ca/facdev/documents/tutorPBL.pdf

4. http://ldt.stanford.edu/ jeepark/jeepark+portfolio/PBL/instructor.htm

adfa, p. 8, 2011.

(C) Springer-Verlag Berlin Heidelberg 2011 